\title{
Persepsi penggunaan gaya manajemen konflik oleh pemimpin terhadap kepuasan anggota di organisasi kemahasiswaan Universitas Udayana
}

\author{
Gusti Ayu Radhaswari Ananda Pinatih dan Naomi Vembriati \\ Program Studi Sarjana Psikologi, Fakultas Kedokteran, Universitas Udayana \\ naomi.vembriati@unud.ac.id
}

\begin{abstract}
Abstrak
Organisasi kemahasiswaan merupakan wahana dan sarana pengembangan diri mahasiswa ke arah perluasan wawasan dan peningkatan kecendekiawanan serta integritas kepribadian untuk mencapai tujuan pendidikan tinggi. Setiap organisasi pasti akan mengalami konflik dan pemimpin mempunyai peran untuk melakukan manajemen konflik, agar konflik yang ada menjadi konflik yang bermanfaat bagi organisasi. Manajemen konflik dapat dilakukan dengan menggunakan gaya yang tepat. Penggunaan gaya manajemen konflik yang tepat tentunya akan membawa kepuasan bagi anggota organisasi. Penelitian ini bertujuan untuk mengetahui persepsi pengunaan gaya manajemen konflik oleh pemimpin terhadap kepuasan anggota di organsasi. Pengambilan sampel dilakukan dengan teknik one stage cluster random sampling. Subjek dalam penelitian ini adalah anggota organisasi kemahasiswaan BEM dan HM di Universitas Udayana yang berjumlah 268 orang. Alat ukur yang digunakan dalam penelitian ini adalah Skala Gaya Manajemen Konflik dan Skala Kepuasan Anggota yang sudah diuji reliabilitas dan validitasnya. Hasil uji regresi menunjukkan koefisien regresi sebesar 0,423 dan koefisien determinasi sebesar 0,176 , dengan signifikasi sebesar $0,000(\mathrm{p}<0,05)$ yang berarti gaya manajemen konflik berperan sebesar 17,6\% dalam menjelaskan kepuasan anggota.
\end{abstract}

Kata kunci: Gaya manajemen konflik, kepuasan anggota, organisasi kemahasiswaan.

\begin{abstract}
The student organizations were a means of self-development students toward the expansion of insight and increased intellect and integrity of personality, to achieve the goal of higher education. Every organization were bound to experience conflict and the leader had a role to perform conflict management, so that the existing conflict becomes a conflict that is beneficial to the organization. Conflict management could be done by using the right sytle. The right conflict management styles would certainly bring satisfaction to the members of the organization. This study aimed to determine the perception of the use of conflict management syles from the leader towards the satisfaction on each member of organization. Samples were done by one stage cluster random sample technique. Subjects on this study were members from BEM and HM at Udayana University, with the total amount of 268 person. The measuring tool on this research were the Conflict Management Style Scale and Satisfaction Scale that have been tested for reliability and validity. Regression test results show regression coefficient of 0.423 and coefficient of determination of 0.176 , with significance of 0.000 ( $p<0.05$ ) which means conflict management style play a role of $17.6 \%$ in explain member job satisfaction.
\end{abstract}

Keywords: Conflict management style, member satisfaction, student organizations. 


\section{LATAR BELAKANG}

Mahasiswa merupakan seseorang yang sedang dalam proses menimba ilmu ataupun belajar dan terdaftar sedang menjalani pendidikan pada salah satu bentuk perguruan tinggi yang terdiri dari akademik, politeknik, sekolah tinggi, institut dan universitas (Hartaji, 2012). Rentang umur mahasiswa mayoritas berada pada 18 hingga 25 tahun. Rentang umur ini, menurut Santrock (2007), masuk ke dalam tahap perkembangan remaja akhir hingga dewasa awal dengan tugas-tugas perkembangan yaitu, mampu bergaul dan bersosialisasi (Gunarsa, 2001). Oleh karena itu, perguruan tinggi mewadahi mahasiswa dengan adanya organisasi kemahasiswaan. Dengan memasuki organisasi kemahasiswaan ini, remaja diharapkan dapat memenuhi tugas perkembangannya dalam hal mampu bergaul serta mempersiapkan diri menuju tahap perkembangan selanjutnya (Gunarsa, 2001; Santrock, 2007).

Tidak jarang perbedaan persepsi atau pandangan di antara individu dalam menerjemahkan misi organisasi terjadi sehingga, menimbulkan pertentangan atau konflik dalam organisasi (Wahyudi, 2015). Kunci dari definisi konflik adalah bahwa pihak yang bertikai mempunyai tujuan yang saling tidak sesuai antara satu sama lain, maka dari situlah konflik timbul sebagai akibat dari ketidaksesuaian tujuan tersebut (Tjosvold dalam Riggio, 2009).

Pada saat ini, sejumlah ahli beranggapan bahwa konflik dalam organisasi tidak dapat dihindarkan, dapat memperjelas masalah, mengetahui kekurangan organisasi, serta solusi terhadap kelemahan yang dapat mengarahkan pada tujuan organisasi. Pandangan ini disebut dengan pandangan interaksionis. Pandangan ini bukan berpendapat bahwa seluruh konflik adalah baik, namun konflik yang fungsional akan mendukung tujuan kelompok, meningkatkan kinerjanya dan bahkan merupakan bentuk konflik yang bersifat konstruktif (membangun). Konflik yang merintangi kinerja kelompok bersifat destruktif (menghancurkan) atau konflik disfungsional (Robbins dan Judge, 2015). Tugas pemimpinlah untuk mengelola konflik agar dapat bermanfaat guna mendorong perubahan dan inovasi dalam organisasi (Wahyudi, 2015).

Salah satu kriteria untuk dapat mencapai viabilitas (keberlangsungan) organisasi adalah proses yang digunakan oleh organisasi atau taktik dalam memanajemen konflik di organisasi (Hackman dan Morris, 1975). Menurut Hackman dan Morris (1975), tiga kriteria viabilitas organisasi adalah kinerja, kepuasan anggota organisasi, taktik dalam memanajemen konflik di organisasi.

Penelitian ini sendiri, akan mengacu pada kriteria viabilitas organisasi yang telah dikemukakan oleh Hackman dan Morris (1975) diatas. Namun, akan lebih dikhususkan pada persepsi peranan gaya manajemen konflik terhadap kepuasan anggota. Hal ini diperkuat dengan hasil penelitian Maynard, Marsh dan Ruddy (2007), yang mencatat bahwa proses interpersonal (manajemen konflik) terbukti berhubungan dengan level kepuasan anggota individu dalam organisasi.
Selain itu, Behfar, Mannix, dan Peterson (2008), juga mengatakan bahwa cara untuk menerapkan strategi untuk menyelesaikan konflik (gaya manajemen konflik) yang berbeda seringkali diasosiasikan dengan pola yang berbeda dari perubahan dalam kepuasan anggota.

Penelitian Peterson (1997) menyatakan bahwa menjaga kepuasan anggota organisasi merupakan hal yang penting karena anggota yang puas akan organisasi, cenderung akan membantu organisasi dalam mewujudkan tujuan organisasi. Disini dapat dilihat bahwa manajemen konflik merupakan hal yang perlu dilakukan untuk menjaga kepuasan anggota. Pemimpin dalam organisasi juga turut andil dalam kepuasan anggota. Hal ini diperkuat dengan hasil penelitian bahwa menjaga kepuasan anggota organisasi merupakan fungsi penting dari kepemimpinan, karena anggota yang merasa puas karena pemikiran mereka dianggap akan lebih mungkin untuk mendukung organisasi dan membantu mengimplementasikan keputusan-keputusan yang dibuat (Strogdill, 1948: Strogdill dan Coons, 1957; Tyler dan Lind, 1988).

Hasil penelitian dari Behfar, Mannix dan Peterson (2008), menyatakan bahwa kelompok-kelompok yang secara konsisten menunjukkan tingkat kinerja yang tinggi disertai dengan tingkat kepuasan anggota yang tinggi dapat memenuhi ketiga kriteria viabilitas organisasi yang disampaikan oleh Hackman dan Morris (1975). Gaya manajemen konflik yang digunakan pada penelitian Behfar, dkk., (2008) adalah accommodating, collaborating dan compromising.

Dipilihnya Universitas Udayana karena, penelitian ini mengacu pada hasil studi pendahuluan melalui wawancara, yang dimana subjek dalam studi pendahuluan ini adalah anggota-anggota organisasi kemahasiswaan di Universitas Udayana. Dalam studi pendahuluan tersebut didapatkan hasil bahwa memang terdapat konflik antara anggota di organisasi-organisasi kemahasiswaan Universitas Udayana. Tidak jarang konflik yang ada berpengaruh negatif terhadap program kerja dan organisasi, sehingga para subjek merasa bahwa perlu adanya manajemen konflik yang tepat dalam menangani konflik. Hasil dari studi pendahuluan tersebut juga mengatakan bahwa pemimpin mempunyai peranan yang besar dalam melakukan manajemen konflik di organisasi (Pinatih, 2017). Maka dari itu, tujuan dalam penelitian ini adalah untuk mengetahui bagaimana persepsi penggunaan gaya manajemen konflik oleh pemimpin terhadap kepuasan anggota di organisasi kemahasiswaan Universitas Udayana.

\section{METODE PENELITIAN}

\section{Variabel dan Definisi Operasional}

Variabel dalam penelitian ini adalah persepsi gaya manajemen konflik sebagai variabel bebas dan kepuasan anggota sebagai variabel tergantung. Definisi operasional dari masing-masing variabel adalah sebagai berikut ini: Persepsi gaya manajemen konflik

Suatu proses menerima, memahami dan mengintrepretasikan kesan atau informasi yang diperoleh 
oleh anggota organisasi mengenai gaya yang digunakan dalam mengatur, mengelola atau mengakhiri berbagai konflik atau pertentangan yang dihadapi dalam mencapai tujuan organisasi yang telah ditetapkan. Penelitian ini akan menggunakan tiga gaya manajemen konflik dari Thomas dan Kilmann (1977) yaitu, gaya collaborating, compromising dan accommodating. Hal ini mengacu pada hasil dari penelitian oleh Behfar, dkk. (2008). Hasil skor nantinya akan menunjukkan tinggi rendahnya persepsi anggota pada penggunaan tiga gaya manajemen konflik diatas.

$\underline{\text { Kepuasan anggota }}$

Menurut Peterson (dalam Behfar dkk., 2008) kepuasan anggota adalah kepuasan bekerja dalam organisasi, menyukai anggota lain dalam organisasi, persepsi keramahan pada anggota organisasi, kesediaan untuk bekerjasama lagi dengan organisasi di masa yang akan datang, persepsi mengenai kepuasan anggota organisasi lain dalam kelompok. Organisasi kemahasiswaan

Kepmendikbud (Keputusan Menteri Pendidikan dan Kebudayaan) RI. No. 155/U/1998 Tentang Pedoman Umum Organisasi Kemahasiswaan di Perguruan Tinggi menyatakan bahwa organisasi kemahasiswaan intra-perguruan tinggi adalah wahana dan sarana pengembangan diri mahasiswa ke arah perluasan wawasan dan peningkatan kecendikiaan serta integritas kepribadian untuk mencapai tujuan pendidikan tinggi.

Penelitian ini akan lebih memfokuskan pada organisasi kemahasiswaan BEM dan HM di fakultas. Penelitian ini memilih untuk menggunakan BEM dan HM karena pada setiap fakultas pasti terdapat kedua organisasi tersebut. Jadi, BEM dan HM dianggap dapat mewakili organisasi kemahasiswaan.

\section{Subjek}

Populasi yang digunakan pada penelitian ini adalah 268 orang anggota organisasi kemahasiswaan Badan Eksekutif mahasiswa (BEM) dan Himpunan Mahasiswa (HM) yang ada di Universtas Udayana. Subjek dalam penelitian ini memiliki karakteristik antara lain periode kepemimpinan dalam organisasi telah berlangsung selama enam bulan atau lebih, subjek merupakan mahasiswa aktif di Universitas Udayana, dan subjek merupakan anggota di dalam organisasi kemahasiswaan masing-masing.

Pada penelitian ini yang akan digunakan Probability Sampling dengan cluster random sampling lalu one stage sampling (Sugiyono, 2012). Jumlah sampel minimum dalam penelitian ini adalah 95 orang yang didapat dengan menggunakan formula dari Slovin.

\section{Tempat dan Waktu Penelitian}

Berdasarkan hasil pengundian, organisasi yang dijadikan sampel adalah BEM Fakultas Kedokteran, BEM Fakultas Matematika dan Ilmu Pengetahuan Alam, BEM Fakultas Ilmu Budaya, BEM Fakultas Teknik, BEM Fakultas Ekonomi, BEM Fakultas Hukum, BEM Fakultas Ilmu Politik dan Sosial, HM Hubungan Internasional, HM Teknologi Informatika, HM Teknik Elektro, dan HM Teknik Sipil.
Pengambilan data dilakukan pada 14 hingga 30 Mei 2018. Penelitian dilakukan dengan melakukan briefing kepada seluruh koordinator masing-masing organisasi tentang tujuan penelitian dan tata cara penelitian. Kemudian, koordinator masing-masing kelas mendistribusikan kuesioner kepada anggota lain dalam organisasinya dan mengumpulkan kembali kuesioner yang telah diisi. Kuesioner dalam penelitian ini terdiri dari informed consent, identitas subjek, petunjuk pengisian Skala I, Skala I (Gaya Manajemen Konflik), petunjuk pengisian Skala II, dan Skala II (Kepuasan Anggota).

\section{Alat Ukur}

Terdapat dua skala yang digunakan dalam penelitian ini yaitu, skala gaya manajemen konflik dan skala kepuasan anggota. Kedua skala tersebut menggunakan jenis skala Likert yang terdiri dari empat pilihan jawaban, yaitu sangat sesuai (SS), sesuai (S), tidak sesuai (TS), dan sangat tidak sesuai (STS). Skala Likert digunakan untuk mengukur sikap, pendapat, dan persepsi seseorang atau kelompok orang tentang fenomena sosial (Sugiyono, 2011). Skala gaya manajemen konflik disusun berdasarkan Thomas-Kilmann Conflict Mode Instrument (Thomas dan Kilmann, 2002). Skala kepuasan anggota disusun berdasarkan aspek dan aitem menurut Peterson (dalam Behfar, dkk., 2008).

Menurut Azwar (2015) alat ukur yang valid dan reliabel adalah syarat untuk mampu memberikan informasi dan hasil data yang akurat. Pengukuran terhadap validitas isi dalam penelitian ini dapat dilakukan dengan teknik professional judgement. Proses pengujian validitas konstruk dilakukan dengan melakukan seleksi pada aitem-aitem skala berdasarkan korelasi aitem-total. Menurut Cronbach (dalam Azwar, 2015) koefisien korelasi aitem-total sama dengan atau lebih besar daripada 0.30 dianggap sudah memuaskan.

Hasil uji validitas skala gaya manajemen konflik memiliki koefisien korelasi aitem-total berkisar antara 0,300 sampai 0,780. Hasil uji reliabilitas skala gaya manajemen konflik dengan menggunakan teknik Cronbach Alpha menunjukkan koefisian alpha $(\alpha)$ adalah 0,919 memiliki arti bahwa skala gaya manajemen konflik mampu mencerminkan 91,9\% variasi skor murni subjek. Hasil uji validitas skala kepuasan anggota memiliki koefisien korelasi aitem-total berkisar antara 0,566 sampai 0,724. Hasil uji reliabilitas skala kepuasan anggota dengan menggunakan teknik Cronbach Alpha menunjukkan koefisian alpha $(\alpha)$ adalah 0,845 memiliki arti bahwa skala pola asuh autoritatif mampu mencerminkan $84,5 \%$ variasi skor murni subjek.

\section{Teknik Analisis Data}

Sebelum melakukan uji hipotesis data penelitian maka perlu dilakukan uji asumsi terlebih dahulu seperti uji normalitas dan uji linearitas. Uji normalitas data penelitian dilakukan dengan uji Kolmogorov-Smirnov. Uji linearitas data penelitian dilakukan dengan menggunakan analisis compare mean, lalu menggunakan test of linearity. Uji hipotesis pada penelitian ini menggunakan teknik uji regresi sederhana. Analisis data penelitian ini dilakukan dengan bantuan 
perangkat lunak SPSS 17.

\section{HASIL PENELITIAN}

\section{Karakteristik Subjek}

Total subjek dalam penelitian ini berjumlah 268 orang, yang terdiri dari 135 orang laki-laki dan 133 orang perempuan. Mayoritas subjek yang mengikuti penelitian ini berada pada organisasi BEM dengan persentase sebesar $64,55 \%$ serta sebanyak 40,67\% mayoritas subjek berada pada semester empat.

\section{Deskripsi Data Penelitian}

Hasil deskripsi data penelitian yaitu gaya manajemen konflik dan kepuasan anggota dapat dilihat pada Tabel 1 (terlampir). Dari hasil deskripsi statistik pada tabel 1 dapat dilihat bahwa gaya manajemen konflik memiliki mean teoritis sebesar 57,5 dan mean empiris sebesar 73,19. Perbedaan mean empiris dan mean teoritis variabel gaya manajemen konflik adalah sebesar 15,69 dengan nilai t sebesar 26,916 $(\mathrm{p}=0,000)$. Mean empiris yang diperoleh lebih tinggi dari mean teoritis (mean empiris < mean teoritis) sehingga dapat disimpulkan bahwa subjek memiliki persepsi bahwa pemimpin dalam organisasinya menggunakan gaya manajemen konflik collaborating, compromising dan accommodating yang tinggi. Tabel 1 menunjukkan sebaran teoritis berada pada rentang 23-92. Kepuasan anggota pada tabel 1 memiliki mean teoritis sebesar 12,5 dan mean empiris sebesar 15,94. Perbedaan mean empiris dan mean teoritis variabel kepuasan anggota adalah sebesar 3,44 dengan nilai t sebesar 23,994 ( $\mathrm{p}=0,000)$. Mean empiris yang diperoleh lebih tinggi dari mean teoritis (mean empiris < mean teoritis) sehingga dapat disimpulkan bahwa subjek memiliki kepuasan yang tinggi. Tabel 1 menunjukkan sebaran teoritis kepuasan anggota berada pada rentang 5-20.

\section{Uji Asumsi}

\section{Uji Normalitas}

Uji normalitas dalam penelitian yang digunakan untuk mengetahui apakah data dapat berdistribusi normal (Sugiyono, 2016). Uji normalitas dalam model regresi dilakukan untuk mengetahui apakah nilai residual prediktor memiliki distribusi normal atau tidak. Nilai normalitas dalam model regresi, tidak dilihat dari normalitas masing-masing variabel yang akan diteliti, namun dilihat dari normalitas residu seluruh variabel yang akan diteliti (Ghozali, 2016). Data dari masing-masing variabel akan dicari nilai unstandardized residualnya. Nilai unstandardized residual ini yang kemudian dimasukkan dalam pengujian Kolmogorov Smirnov (Ghozali, 2005). Nilai residual dapat disimpulkan berdistribusi normal jika nilai signifikansi lebih besar dari 0.05 ( $>0.05$ ) (Riadi, 2016). Berdasarkan tabel 2 (terlampir), didapatkan hasil $\mathrm{p}$ sebesar 0,059 sehingga penelitian ini memiliki data yang berdistribusi normal $(\mathrm{p}>0,05)$.

\section{Uji Linearitas}

Uji linieritas dilakukan untuk mengetahui apakah hubungan antara variabel bebas dan variabel tergantung yang diteliti bersifat linier atau tidak. Uji linieritas dalam penelitian ini menggunakan uji compare means, kemudian test for linearity. Pembuktian untuk mengetahui apakah terdapat hubungan yang linier atau tidak antara variabel bebas dengan variabel tergantung pada penelitian ini didasarkan pada taraf signifikansi pada Linearity. Apabila taraf signifikansi pada Linearity lebih kecil dari $0,05(\mathrm{p}<0,05)$, maka dikatakan terdapat hubungan yang linier antara kedua variabel. (Santoso, 2014). Hasil pengujian linieritas dapat dilihat dirangkum dalam Tabel 3 (terlampir).

Hasil uji linieritas pada tabel 3 menunjukkan taraf signifikansi Linearity pada variabel kepuasan anggota dan gaya manajemen konflik sebesar 0,000. Berdasarkan hasil tersebut, maka disimpulkan bahwa terdapat hubungan yang linier antara variabel kepuasan anggota dengan gaya manajemen konflik. Hal ini, karena taraf signifikansi Linearity yang diperoleh lebih kecil dari 0,05 ( $<<0,05)$.

\section{Uji Hipotesis}

Uji hipotesis yang dilakukan dalam penelitian ini menggunakan teknik analisis regresi sederhana. Uji regresi sederhana memiliki tujuan untuk melihat suatu hubungan antara satu variabel bebas dengan variabel tergantung. Pada penelitian ini, uji regresi sederhana dilakukan untuk mengetahui apakah variabel bebas gaya manajemen konflik collaborating, compromising dan accommodating dapat memprediksi munculnya variabel kepuasan anggota pada anggota organisasi. Variabel bebas dikatakan berpengaruh secara signfikan terhadap variabel tergantung jika pada uji regresi, taraf signifikansinya lebih kecil dari $0,05(\mathrm{p}<0,05)$ (Santoso, 2014). Hasil pengujian regresi sederhana dapat dilihat pada Tabel 4(terlampir).

Tabel 4 menunjukkan hasil uji regresi sederhana dengan diperolehnya taraf signifikansi sebesar $0,000(\mathrm{p}<0,05)$. Taraf signifikansi yang lebih kecil dari $0,05(\mathrm{p}<0,05)$ menunjukkan bahwa Ho ditolak dan Ha diterima. Diterimanya hipotesis memiliki arti bahwa model regresi dalam penelitian ini dapat digunakan untuk memprediksi kepuasan anggota organisasi atau dapat dikatakan bahwa gaya manajemen konflik collaborating, compromising dan accommodating berperan terhadap kepuasan anggota organisasi.

Selanjutnya dalam penelitian ini hasil uji regresi sederhana juga digunakan untuk melihat besarnya peran gaya manajemen konflik collaborating, compromising dan accommodating terhadap kepuasan anggota organisasi. Besarnya peran dari gaya manajemen konflik collaborating, compromising dan accommodating terhadap kepuasan anggota organisasi tersebut dapat dilihat pada Tabel 5 (terlampir).

Tabel 5 menunjukkan diperoleh koefisien regresi $(\mathrm{R})$ sebesar 0,423 dan koefisien determinasi ( $R$ Square) sebesar 0,179. Perolehan koefisien regresi $(\mathrm{R})$ sebesar 0,423 menunjukkan bahwa terdapat hubungan positif antara variabel bebas yaitu gaya manajemen konflik terhadap kepuasan anggota organisasi. Perolehan koefisien determinasi ( $R$ Square) sebesar 0,179 menunjukkan bahwa gaya manajemen konflik memberikan peran sebesar $17,9 \%$ terhadap kepuasan anggota 
organisasi, sedangkan sisanya sebesar $82,1 \%$ ditentukan oleh faktor-faktor lain yang tidak diteliti.

Uji analisis regresi sederhana pada penelitian ini juga dapat digunakan untuk mengetahui peran variabel bebas terhadap variabel tergantung dan untuk menemukan garis regresi. Uji hipotesis minor dan garis regresi sederhana dapat dilihat pada Tabel 6 (terlampir).

Penelitian ini menggunakan satu variabel bebas, sehingga diperoleh persamaan garis regresi yaitu: $Y=8,328+0,104 \mathrm{X}$ Keterangan:

$\mathrm{Y} \quad$ : Kepuasan anggota organisasi

$\mathrm{X} \quad$ : Gaya manajemen konflik

Persamaan garis regresi tersebut memiliki arti sebagai berikut:

a. Konstanta sebesar 8,328 menyatakan bahwa jika tidak ada penambahan atau peningkatan skor pada variabel gaya manajemen konflik, maka taraf kepuasan anggota organisasi sebesar 8,328.

b. Koefisien regresi $\mathrm{X}$ sebesar 0,104 menyatakan bahwa setiap penambahan atau peningkatan satuan nilai subjek pada variabel gaya manajemen konflik, maka akan terjadi kenaikan taraf kepuasan anggota organisasi sebesar 0,104 .

Ringkasan hasil uji hipotesis dalam penelitian ini, dapat dilihat pada Tabel 7 (terlampir).

\section{PEMBAHASAN DAN KESIMPULAN}

Dari hasil penelitian yang telah dilakukan, sebanyak 134 subjek dari total 268 subjek, berada pada kisaran skor total diatas 75 (sangat tinggi), dan sebanyak 104 subjek berada pada kisaran skor total 59 hingga 75 (tinggi), yang dimana mempunyai dapat disimpulkan bahwa 238 subjek atau $88,8 \%$ subjek, mempunyai persepsi bahwa pemimpin dalam organisasinya menggunakan gaya manajemen konflik collaborating, compromising dan accommodating. Sebanyak 100 subjek berada pada skor total di atas 16 (kategori sangat tinggi) dan sebanyak 140 subjek berada pada skor total 13 hingga 16 (kategori tinggi). Totalnya, 140 dari 268 subjek atau sekitar 89,5\% subjek menyatakan puas sebagai anggota dalam organisasinya saat ini. Kesimpulan yang dapat diambil bahwa sebagian besar subjek mempunyai persepsi pemimpin dalam organisasinya menggunakan gaya manajemen konflik collaborating, compromising dan accommodating, dan merasa puas dengan organisasinya.

Berdasarkan hasil hipotesis dengan menggunakan uji analisis regresi sederhana, diperoleh hasil bahwa hipotesis diterima $(\mathrm{R}=0,423, \mathrm{p}<0,05)$. Hipotesis yang diterima berbunyi bahwa gaya manajemen konflik yang digunakan pemimpin berperan terhadap kepuasan anggota dalam organisasi kemahasiswaan BEM (Badan Eksekutif Mahasiswa) dan HM (Himpunan Mahasiswa) di Universitas Udayana. Dapat diterimanya hipotesis tersebut dilihat dari hasil analisis statistik yang menggunakan teknik analisis regresi sederhana.

Adanya peran dari gaya manajemen konflik terhadap kepuasan anggota organisasi, seperti pada hasil penelitian ini, didukung oleh penelitian yang dilakukan oleh Behfar, dkk. (2008) yang menjadi acuan dalam penelitian ini. Penelitian Behfar, dkk. sendiri menyatakan bahwa kelompok-kelompok secara konsisten menunjukkan tingkat kinerja yang tinggi disertai dengan tingkat kepuasan anggota yang tinggi dengan penggunaan gaya manajemen collaborating, compromising dan accommodating, maka ketiga gaya manajemen konflik itulah yang kemudian digunakan dalam penelitian ini. Tiga dari lima gaya ini, merupakan hasil pengembangan oleh Thomas dan Kilmann (1977). Dua gaya lain yang tak digunakan dalam penelitian ini adalah competing dan avodiding.

Manajemen konflik sendiri adalah penggunaan dari resolusi dan teknik stimulasi untuk mencapai level konflik yang diinginkan (Robbins, 2015). Tugas pemimpinlah untuk melakukan manajemen konflik agar dapat bermanfaat guna mendorong perubahan dan inovasi dalam organisasi (Wahyudi, 2015). Manajemen konflik, merupakan hal yang sangat penting untuk memperkirakan hubungan kinerja dengan konflik antar dua orang (Jehn \& Bendersky; Marks, Mathieu, \& Zaccaro; Mathieu \& Schulze; Tinsley; Weingart; Williams \& O’Reilly dalam Behfar, dkk., 2008).

Gaya manajemen konflik yang tepat, merupakan salah satu dari tiga kriteria viabilitas (keberlangsungan) organisasi (Hackman dan Morris, 1975). Oleh karena itu, penting bagi suatu organisasi untuk memperhatikan gaya manajemen konflik apa yang akan digunakan dalam melakukan manejemen konflik, terutama bagi pemimpin, seperti yang telah dikatakan Wahyudi (2015) diatas.

Selain gaya manajemen konflik yang merupakan satu dari tiga faktor viabilitas organisasi menurut Hackman dan Morris (1975), faktor lainnya adalah kepuasan anggota organisasi. Hal ini juga dikuatkan oleh Barrick, dkk. (2007); Balkundi dan Harrison (2006) bahwa, viabilitas organisasi, seringkali dikombinasikan dengan afeksi atau sikap. Contohnya seperti kepuasan anggota, komitmen anggota dan kohesivitas organisasi sebagai indikator dari viabilitas organisasi (Barrick, dkk. 2007; Balkundi dan Harrison, 2006). Bushe dan Coetzer (2007) membagi viabilitas kelompok kedalam dua dimensi yaitu, kepuasan anggota dengan keanggotaan dan kepuasan anggota dengan keluaran yang dihasilkan. Hal ini sejalan dengan hasil penelitian, dimana mayoritas subjek merasa puas dengan organisasinya. Dapat kita kaitkan kepuasan anggota dalam organisasi sebagai terpenuhinya viabilitas organisasi seperti yang telah disebutkan di atas.

Hackman (1987) membagi definisi viabiltas organisasi kedalam dua konstruk. Kemampuan dari anggota organisasi untuk bekerjasama lagi di kemudian hari dan kebutuhan kepuasan anggota kelompok. Kedua konstruk ini sudah terpenuhi di dalam penelitian, yang dimanisfestasikan dalam bentuk aitem-aitem skala kepuasan dengan hasil mayoritas subjek merasa puas.

Para peneliti menemukan bahwa kepuasan anggota 
organisasi dan viabilitas (keberlangsungan) organisasi merupakan komponen penting dari efektivitas organisasi (Taeklab, dkk. 20019; Sundstrom, dkk. 1990; Campion, dkk. 1993; Bushed an Coetzer, 2007; McGrath, 1984). Hackman dan Morris (1975) sendiri, juga mengutarakan bahwa viabilitas organisasi dan kepuasan anggota organisasi merupakan faktor penting dari efektivitas organisasi. Menurut mereka lebih lanjut, viabilitas organisasi merupakan kapasitas organisasi untuk melanjutkan kinerjanya secara efektif di masa depan.

Dalam penelitiannya, Peterson (1997) menyatakan bahwa menjaga kepuasan anggota organisasi merupakan hal yang penting karena anggota yang puas akan organisasinya, cenderung akan membantu organisasi dalam mewujudkan tujuan organisasi. Selanjutnya, terdapat lima aspek menurut Peterson (dalam Behfar dkk., 2008) dalam menentukan kepuasan anggota, yaitu, kepuasan anggota bekerja dalam organisasi, menyukai anggota lain dalam organisasi, persepsi keramahan dalam anggota organisasi, kesediaan untuk bekerjasama lagi dengan organisasi di masa yang akan datang, serta persepsi mengenai kepuasan anggota organisasi lain dalam kelompok.

Seperti yang telah disebutkan sebelumnya, bahwa kepuasan anggota organisasi dipengaruhi oleh gaya manajemen konflik yang digunakan. Hal ini diperkuat dengan hasil penelitian Maynard, Marsh dan Rudy (2007) yang mencatat bahwa proses interpersonal (manajemen konflik) terbukti berhubungan dengan level kepuasan anggota individu dalam organisasi. Selain itu, Behfar, dkk. (2008), juga mengatakan bahwa cara untuk menerapkan strategi untuk menyelesaikan konflik (gaya manajemen konflik) yang berbeda seringkali diasosiasikan dengan pola yang berbeda dari perubahan dalam kepuasan anggota.

Sedangkan, berdasarkan hasil analisis uji regresi sederhana yang telah dilakukan, diperoleh hasil bahwa gaya manajemen konflik yang digunakan pemimpin mempunyai peran yang signifikan terhadap kepuasan anggota pada organisasi kemahasiswaan BEM dan HM di Universitas Udayana. Hal ini dibuktikan dengan koefisien regresi sebesar 0,423 dan nilai $F$ sebesar 57,923 dengan taraf signifikansi sebesar 0,000. Koefisien determinasi dalam penelitian ini adalah sebesar 0,179 yang berarti gaya manajemen konflik memberikan peran sebanyak $17,9 \%$ terhadap kepuasan anggota. Sisanya terdapat $82,1 \%$ peran yang diberikan faktor-faktor lain terhadap kepuasan anggota pada organisasi kemahasiswaan BEM dan HM di Universitas Udayana.

\section{Kesimpulan}

Berdasarkan penelitian dan analisis data yang telah dilakukan, maka dapat ditarik kesimpulan sebagai berikut:

1. Gaya manajemen konflik collaborating, compromising, dan accomodating yang digunakan oleh pemimpin dipersepsikan mempunyai peran terhadap kepuasan anggota pada organisasi kemahasiswaan di Universitas Udayana.
2. Mayoritas subjek penelitian mempunyai persepsi bahwa pemimpin organisasinya telah menggunakan gaya manajemen konflik collaborating, compromising dan accommodating.

3. Mayoritas subjek penelitian, merasa puas dengan organisasinya saat ini.

\section{Saran}

Beberapa saran yang dapat peneliti ajukan terkait penelitian ini adalah:

$\underline{\text { Saran Praktis }}$

a. Agar pemimpin-pemimpin organisasi kemahasiswaan di Universitas Udayana menggunakan gaya manajemen konflik collaborating, compromising dan accommodating dalam menangani konflik yang ada di organisasi dikarenakan telah terbukti berperan meningkatkan kepuasan anggota.

b. Gaya manajemen konflik tidak berperan sepenuhnya dalam menentukan kepuasan anggota, sebaiknya, pemimpin organisasi juga memperhatikan faktor-faktor lainnya.

$\underline{\text { Saran Bagi Penelitian Selanjutnya }}$

a. Berdasarkan hasil penelitian yang dilakukan, terdapat banyak variabel lain yang mempengaruhi variabel kepuasan anggota, penelitian selanjutnya dapat meneliti variabel lainnya yang tidak disebutkan dalam penelitian ini.

b. Penelitian selanjutnya dapat lebih mengkhususkan karakteristik subjek penelitian kepada pengurus organisasi saja, untuk mendapat gambaran yang lebih konkret mengenai gaya manajemen konflik yang digunakan oleh pemimpin.

c. Peneliti selanjutnya dapat lebih memperhatikan kelengkapan subjek dalam mengisi kuisioner, agar tidak banyak kuisioner yang gugur dalam penelitian.

\section{DAFTAR PUSTAKA}

Aamodt, G. M. (2010). Industrial/Organizational Psychology: An Applier Approach (Sixth Edition). Canada:Wordsworth, Cengage Learning.

Azwar, S. (2010). Penyusunan Skala Psikologi. Jogjakarta: Pustaka Pelajar.

Azwar, S. (2010). Reliabilitas dan Validitas. Jogjakarta: Pustaka Pelajar.

Azwar, S. (2015). Realiabilitas dan Validitas (Edisi IV). Yogyakarta: Pustaka Pelajar.

Balkundi, P., Harrison, D. A. (2006). Ties, Leaders, and Time in Teams: Strong Inference about Network Structure's Effects on Team Viability and Performance. Academy of Management Journal, 49, 49-68.

Barrick, M. B., Bradley, B. H., Kristof-Brown, A.L., Colbert, A. E. (2007). The Moderating Role of Top Management Team Interpendence: Implications for Real Teams and Working Groups. Academy of Management Journal, 50, 544-557.

Behfar, J. K., Mannix, E. A., Peterson, R. S. (2008). The Critical Role of Conflict Resolution in Terms: A Close Look at the Links Between Conflict Type, Conflict Management Strategies, and Terms Outcomes. Journal of Applied 
Psychology, 93(1), 170-188.

Bushe, G. R., Coetzer, G. H. (2007). Group Development and Team Effectiveness. The Jurnal of Applied Behavioral Science, 43(2), 184-212.

Campion, M. A., Medsker, G. J., Higgs, A. C. (1993). Relations between Work Group Characteristic and Effectiveness: Implications for Designing Effective Work Group. Personel Psychology, 46, 823-847.

Davis, K., Newstrom, J. W. (1985). Perilaku dalam Organisasi. Jakarta: Erlangga.

Field, A. (2009). Discovering Statistics Using IBM SPSS Statistics (4th ed). London: SAGE Publications Ltd.

Gozhali, I. (2005). Aplikasi Analisis Multivariate Dengan Program SPSS. Semarang: Badan Penerbit Undip.

Gunarsa, S. D, \& Gunarsa, Y. S. D. 2001. Psikologi Perkembangan Anak dan Remaja. Jakarta: BPK Gunung Mulia.

Hackman, J. R. (1987). The Design of Work Teams. Handbook of Organizational Behavior, 315-342.

Hackman, J. R., Wageman, R. (2005). When and How Team Leaders Matter. Research in Organizational Behavior, 26, 37-74.

Hackman, J. R., Morris, C. G. (1975). Groups Tasks, Group Interaction Process and Group Perfomance Effectiveness: A Review and Proposed Integration. Adrames In Experimental Social Psychology, 8, 45-98.

Hadi, S. (2004). Statistika. Jilid 2. Jogjakarta: Andi.

Handoko, T. H. (1984). Dasar-dasar Manajemen Produksi. Yogyakarta: BPFE.

Handoko, T. H. (2001). Manajemen Personalia dan Sumber Daya Manusia. Yogyakarta: BPFE.

Hartaji, D. (2012). Motivasi Berprestasi pada Mahasiswa yang Berkuliah Dengan Jurusan Pilihan Orang Tua. Skripsi. Jakarta: Universitas Gunadarma.

Huismans, E. S., Vliert, E. V. D, Euwema, M. C. (1995). Managing Conflict With a Subordiante or a Superior: Effectiveness of Conglomerated Behavior. Journal of Applied Psychology, 80(2), 271-281.

Irdiansyah, Y. (2012). Pengaruh Gaya Kepemimpinan Terhadap Manajemen Konflik Manajer Perum Peruri. Tesis. Jakarta: Universitas Indonesia. (Diambil dari lib.ui.ac.id/file?file=digital/20333435-T32284Yudhi\%20Irdiansyah.pdf).

Jehn, K. (1997). A qualitative analysis of conflict types and dimensions in organizational groups. Administrative Science Quarterly, 42, 530-557.

Kilmann, H. R. (2011). Thomas-Kilmann Conflict Mode Instrument (CPP Authors Insights). Canada: Psychometrics Canada Ltd.

Kilmann, R. H., \& Thomas, K. W. (1977). Developing a forcedchoice measure of conflict-handling behavior: The MODE instrument. Educational and Psychological Measurement, 37 (2), 309-325.

Kristanto, H. (2015). Hubungan Antara Komitmen Organisasional dan Gaya Manajemen Konflik Karyawan Bank Milik Pemerintah Daerah Tingkat II DI PROVINSI DI. Jurnal Manajemen, Strategi Bisnis dan Kewirahusaan, 9(1), 1-14.

Lind, E. A., \& Tyler, T. (1988). The social psychology of procedural justice. New York: Plenum.

Lumintang, J. (2015). Dinamika Konflik dalam Organisasi. EJournal Acta Diurna, 4(2).

Luthans, F. (2006). Perilaku Organisasi (Edisi Sepuluh). Yogyakarta: PT. Andi.

Luthnas, F., Avolio, B. J., Avey, J. B., Norman, S. M. (2007). Positive Psychological Capital: Measurement and Relationship With Perfomance and Satisfaction. Personnel Psychology, 60, 541-472.
Mangkunegara, A. P. (2005). Sumber Daya Manusia Perubahan. Bandung: Remaja Rosdakarya.

Mathieu, J., Maynard, M. T., Rapp, T., Gilson, L. (2008). Team Effectiveness 1997-2007: A Review of Recent Advancements and a Glimpse Into the Future. Journal of Management, 34(3), 410-476.

Maynard, M. T., Mathieu, J. E., Marsh, W. M., Rudyy, T. M. (2007). A Multilevel Investigation of the Influences of Employees Resistance to Empowerment. Human Performance, 20, 147-171.

McGrath, J. E. (1984). Groups: Interaction and Performance. Englewood Cliffs, NJ: Pretice-Hall.

Munandar, S. A. (2014). Psikologi Industri dan Organisasi. Jakarta: Penerbit Universitas Indonesia (UI-PRESS).

Mohammed, S., Ferzandi, L., Hamilton, K. (2010). Metaphor No More: A 15 Year Review of the Team Mental Model Construct. Journal of Management, 36(4), 876-920.

Papalia, D. E., Olds, S. W., \& Feldman, R. D. (2013). Human Development $\left(10^{\text {th }}\right.$ ed). Jakarta: Penerbit Salemba Humanika.

Pinatih, G. A. R. A. (2017). Efektivitas Gaya Kepemimpinan Demokratis dalam Manajemen Konflik Interpersonal Pada Organisasi Kemahasiswaan Badan Eksekutif Mahasiswa (BEM). Studi Kasus. Bali: Universitas Udayana. Tidak dipublikasikan.

Peterson, S. R. (1997). A Directive Leadership Style in Group Decision Making Can Be Both Virtue and Vice: Evidence From Elite and Experimental Groups. Journal of Personality and Social Psychology, 72(5), 1107-1121.

Peterson, S. R. (1999). Can You Have Too Much of a Good Thing? The Limits of Voice for Improving Satisfaction With Leaders. Personality and Social Psychology Bulletin, 25(3), 313-324.

Peterson, S. R. (2003). The Dynamic Relationship Between Perfomance Feedback, Trust and Conflict in Groups: A Longitudinal Study. Organizational Behavior and Human Decision Processes, 92, 102-112.

Porter, W. L. (2009). Introduction To Industrial/Organizational Psychology (Fifth Edition). Pearson Education International.

Purwanto. (2008). Metodelogi Penelitian Kuantitatif: untuk Psikologi dan Pendidikan. Yogyakarta: Pustaka Pelajar.

Rahim, A. M. (1983). A Measure of Styles of Handling Interpersonal Conflict. Academy of Management Journal, 26(2), 368-376.

Remus, I., Spitzmuller, M., Fulmer, I. S., Johnson, M. D. (2009). Personality and Citizenship Behaviour: The Mediating Role of Job Satisfaction. Journal of Applied Psychology, 94(4), 945-959.

Riadi, E. (2016). Statistika Penelitian (Analaisis Manual dan IBM SPSS). Yogyakarta: ANDI Yogyakarta.

Riduwan. (2012). Pengantar Statistika Sosial. Bandung: Alfabeta.

Riggio, R. E. (2009). Introduction to Industrial/Organizational Psychology (Fifth Edition). New Jersey: Perason Educational International.

Robbins, P. S., Judge, T. A. (2015). Perilaku Organisasi (Edisi XVI). Jakarta Selatan: Penerbit Salemba Empat.

Santoso, S. (2014). Panduan lengkap SPSS versi 20. Jakarta: Elex Media Komputindo.

Santrock, J. W. (2003). Adoloscence: Perkembangan Remaja. Jakarta: Erlangga.

Santrock, J. W. (2007). Remaja (Edisi XI Jilid I). Penerbit Erlangga.

Santrock, J. W. (2007). Remaja (Edisi XI Jilid II). Penerbit Erlangga.

Siagian, S. P. (1992). Fungsi-fungsi Manajerial. Jakarta: Bumi Aksara. 
Sianipar, R. B., Anggie, Haryanti, K. (2014). Hubungan Komitmen Organisasi dan Kepuasan anggota Dengan Intensi Turnover Pada Karyawan Bidang Produksi CV.X. Psikodimensia, 13(1), 98-114.

Siswono, Y. E., Tatag. (2007). Penjenjangan Kemampuan Berpikir Kreatif dan Identifikasi Kemampuan Berpikir Kreatif Siswa dalam Mengajukan dan Memecahkan Masalah Matematika. Disertasi. Surabaya: UNESA.

Stogdill, R. M. 1948. Personal Factors Assosiated with Leadership: A Survey of the Literature. Journal of Psychology, 25, 3571.

Stogdill, R. M., Coons, A. E. (1957). Leader Behavior: It's Description and Measurement. Columbus: The Ohio State University.

Sudarman, P. (2004). Belajar Efektif di Perguruan Tinggi. Bandung: Simbiosa Rekatama Media.

Sugiyono. (2012). Metode Penelitian Kuantitatif, Kualitatif dan Kombinasi (Mixed Methods). Bandung: Alfabeta.

Sugiyono. (2016). Metode Penelitian Kombinasi. Bandung: Alfabeta.

Sukirman, S. (2014). Tuntutan Belajar di Perguruan Tinggi. Jakarta: Pelangi Cendikia.

Sundstrom, E., De Meuse, K. P., Futrell, D. (1990). Work Teams: Applications and Effectiveness. American Psychologist, 45 (2), 120-133

Suryabrata, S. (1995). Sikap Manusia: Teori dan Pengukurannya (Edisi II). Yogyakarta: Pustaka Pelajar.

Suryabrata, S. (1996). Tes Prestasi: Fungsi dan Pengembangan Pengukuran Prestasi Belajar (Edisi II). Yogyakarta: Pustaka Pelajar.

Suryabrata, S. (2006). Metodelogi Penelitian. Jakarta: PT. Raja Grafindo Persada

Suryabrata, S. (2012). Penyusunan Skala Psikologi (Edisi II). Yogyakarta: Pustaka Pelajar.

Somech, A., Desivilya, H. S., Lidogoster, H. (2009). Team Conflict Management and Team Effectiveness: The Effect of Task Interdependence and Team Identification. Journal of Organizational Behavior, 30, 359-378.

Tangkiliasan, N. H. (2005). Manajemen Publik. Jakarta: PT. Gramedia Pustaka Utama.

Taylor, E. S., Peplau, L. A., Sears, D. O. (2009). Psikologo Sosial (Edisi XII). Jakarta: Kencana.

Tekleab, G. A., Quigley, N. R., Tesluk, P. E. (2009). A Longitudinal Study of Team Conflict, Conflict Management, Cohesion, and Team Effectiveness. Groups and Organization Management, 34(2), 170-205.

Thomas, K. (1992). Conflict and negotiation processes in organizations. In M. Dunnette \& L. Hough (Eds.), Handbook of industrial and organiza- tional psychology (Vol. 3, pp. 651-717). Palo Alto, CA: Consulting Psychologists Press.

Thomas, K. W, Kilmann, R. (2002). Thomas-Kilmann Conflict Mode Instrument. Cleveland: CPP, Inc.

Wahyudi, Dr. (2015). Manajemen Konflik dalam Organisasi.

Bandung: Penerbit Alfabeta. 


\section{LAMPIRAN}

Tabel 1.

Deskripsi Statistik Data Penelitian

\begin{tabular}{ccc}
\hline Deskripsi Data & Gaya Manajemen Konflik & Kepuasan anggota \\
\hline N & 268 & 268 \\
Mean Teoretis & 57,5 & 12,5 \\
Mean Empiris & 73,19 & 15,94 \\
Std. Deviasi Teoretis & 11,5 & 2,5 \\
Std. Deviasi Empiris & 9,543 & 2,347 \\
Skor Minimal & 23 & 5 \\
Skor Maksimal & 92 & 20 \\
Sebaran Teoretis & $23-92$ & $5-20$ \\
Sebaran Empiris & $36-92$ & $5-20$ \\
T & 26,916 & 23,994 \\
& $\mathrm{p}=(0,000)$ & $\mathrm{p}=(0,000)$ \\
\hline
\end{tabular}

Tabel 2 .

Hasil Uji Normalitas Kolmogorov Smirnov

\begin{tabular}{ccc}
\hline Kolmogorov Smirnov & $\mathrm{P}$ & Kesimpulan \\
\hline 1,328 & 0,059 & Data Normal \\
\hline
\end{tabular}

Tabel 3.

Hasil Uji Linieritas Data Penelitian

\begin{tabular}{ccccc}
\hline & & $\mathrm{F}$ & Sig. \\
\hline Kepuasan anggota*Gaya & Between & (Combined) & \\
Manajemen Konflik & Group & Linearity & 62,779 & 0,000 \\
& & & \\
\hline
\end{tabular}

Tabel 4.

Hasil Signifikansi Uji Regresi Sederhana

\begin{tabular}{ccccccc}
\hline Model & & Sum of Squares & df & Mean Square & F & Sig. \\
\hline \multirow{4}{*}{1} & Regression & 263,047 & 1 & 263,047 & 57,923 & 0,000 \\
& Residual & 1207,998 & 266 & 4,541 & & \\
& Total & 1471,045 & 267 & & & \\
\hline
\end{tabular}

Tabel 5.

Besaran Peran Variabel Bebas Terhadap Variabel Tergantung

\begin{tabular}{|c|c|c|c|c|}
\hline Model & $\mathrm{R}$ & $R$ Square & Adjusted R Square & $\begin{array}{l}\text { Std. Error of the } \\
\text { Estimate }\end{array}$ \\
\hline 1 & 0,423 & 0,179 & 0,176 & 2,131 \\
\hline
\end{tabular}


Tabel 6.

Uji Garis Regresi Sederhana

\begin{tabular}{|c|c|c|c|c|c|c|}
\hline & \multirow[t]{2}{*}{ Model } & \multicolumn{2}{|c|}{ Unstardardized Coefficients } & \multirow{2}{*}{$\begin{array}{c}\begin{array}{c}\text { Standardized } \\
\text { Coefficients }\end{array} \\
\text { Beta } \\
\end{array}$} & \multirow[t]{2}{*}{$\mathrm{T}$} & \multirow[t]{2}{*}{ Sig. } \\
\hline & & $\mathrm{B}$ & Std. Error & & & \\
\hline & (Constant) & 8,328 & 1,009 & & 8,256 & 0,000 \\
\hline 1 & $\begin{array}{c}\text { Gaya Manajemen } \\
\text { Konflik }\end{array}$ & 0,104 & 0,014 & 0,423 & 7,611 & 0,000 \\
\hline
\end{tabular}

Tabel 7.

Rangkuman Hasil Uji Hipotesis Penelitian

\begin{tabular}{lc}
\hline \multicolumn{1}{c}{ Hipotesis } & Hasil \\
\hline Hipotesis: & Diterima \\
Persepsi penggunaan gaya manajemen konflik oleh & \\
pemimpin berperan terhadap kepuasan anggota dalam & \\
organisasi kemahasiswaan BEM (Badan Eksekutif & \\
Mahasiswa) dan HM (Himpunan Mahasiswa) di & \\
Universitas Udayana. & \\
\hline
\end{tabular}

